\title{
Avaliação de políticas de combate à pobreza no Brasil: aplicação do método de Controle Sintético Generalizado para o Fecop no Ceará
}

Evaluation of policies to combat poverty in Brazil: application of the Generalized Synthetic Control method for Fecop in Ceará

\author{
Vitor Hugo Miro C. Silva (1) \\ Francisca Zilânia Mariano (1) \\ Guaracyane Lima Campêlo(") \\ Natália Cecilia de França(2) \\ João Mário Santos de França( ${ }^{(1)}$ \\ Marília Rodrigues Firmiano (2)
}

\author{
(1) Universidade Federal do Ceará \\ (2) Instituto de Pesquisa e Estratégia \\ Econômica do Ceará
}

\section{Abstract}

The objective of this study is to estimate the impact of the creation of the State Fund to Combat Poverty (FECOP) in 2003 on poverty indicators in Ceará. The empirical application is distinguished by the use of the Generalized Synthetic Control method recently developed by Xu (2017). With statelevel data for the period 1981 to 2014, the results indicate a statistically significant impact of FECOP on poverty and extreme poverty reduction in Ceará starting in 2008. Additionally, a comparative analysis of states composing the synthetic control for Ceará was carried out, regarding the number and total value of benefits of the Program Bolsa Familia. The purpose is to present evidence that the effects found are not being affected by federal program transfers.

\section{Keywords}

Generalized Synthetic Control, Poverty, State Fund to Combat Poverty.

JEL Codes C13, C21, I32.

\section{Resumo}

O objetivo deste artigo é estimar o impacto da criação do Fundo Estadual de Combate à Pobreza (FECOP), em 2003, sobre indicadores de pobreza no Ceará. A aplicação empírica diferencia-se pelo uso do método de Controle Sintético Generalizado, recentemente desenvolvido por Xu (2017). Com dados em nivel estadual para o periodo de 1981 a 2014, os resultados indicam um impacto estatisticamente significativo do FECOP sobre a redução da pobreza e extrema pobreza no Ceará a partir de 2008. Adicionalmente, realizou-se uma análise comparativa dos estados utilizados na simulação do controle sintético com o Ceará, no que diz respeito ao número e valor total de beneficios do Programa Bolsa Família. O intuito é apresentar evidências de que os efeitos encontrados não estão sendo afetados pelos repasses do programa federal.

\section{Palavras-chave}

Controle Sintético Generalizado, pobreza, Fundo Estadual de Combate à Pobreza.

Códigos JEL C13, C21, I32. 


\section{Introdução}

A pobreza no Brasil, embora bastante discutida, ainda é foco de debates na literatura que visam identificar os principais fatores que a afetam e que possam reduzi-la. Existem diversas formas de mensurá-la, entre elas, a mais intuitiva é a proporção de pobres, calculada com base no percentual de pessoas que possuem renda domiciliar per capita inferior à linha de pobreza adotada na análise.

Existe um debate consolidado sobre desenvolvimento econômico, em que a expansão da renda por si só pode não ser suficiente para reduzir a pobreza (França; Manso; Barreto, 2012). Segundo Adelman e Morris (1973) e Chenery et al. (1974), as evidências mostram que os indivíduos mais pobres em economias menos desenvolvidas pouco se beneficiaram durante $\mathrm{o}$ período de crescimento da renda em seus países.

A literatura sobre a redução da pobreza aponta para uma forte contribuição da redução da desigualdade de renda que, por sua vez, tem como principais determinantes as mudanças demográficas, melhoras nos indicadores de emprego e de rendimentos, além do efeito do Programa Bolsa Família (PBF). Evidências no Brasil sobre esses determinantes podem ser encontradas em Soares (2006), Soares et al. (2006), Hoffmann (2006), Barros et al. (2006), Barros et al. (2007), Barros et al. (2010), Marinho, Linhares e Campêlo (2011), Hoffmann e Oliveira (2014), entre outros.

Apesar das estratégias e políticas de combate à pobreza aplicadas pelo Governo Federal (Programa Bolsa Família/Plano Brasil sem Miséria), torna-se imperativa a aplicação de políticas que considerem as disparidades regionais. Ações no âmbito do Plano Brasil sem Miséria podem alcançar determinado impacto na região Sul do país, em estados como Santa Catarina, mas resultados de mesma magnitude e qualidade podem não ser observados em estados da região Nordeste, como o Ceará. Nesse sentido, políticas locais podem complementar os esforços já realizados em âmbito nacional.

Entre as iniciativas em âmbito subnacional, o presente estudo destaca a experiência do estado do Ceará, onde existe um considerável esforço para a elaboração de uma política estadual de combate à pobreza. Grande parte desse esforço é financiado com recursos do Fundo Estadual de Combate à Pobreza (FECOP).

Os Fundos de Combate à Pobreza (FCP) foram concebidos a partir da Emenda Constitucional n ${ }^{\circ} 31$, de 14 de dezembro de 2000, que alterou 
o Ato das Disposições Constitucionais Transitórias (ADCT) da Constituição Federal. Regulamentados por meio da Lei Complementar n ${ }^{\circ} 111$ de 6 de julho de 2001 para vigorar até 2010, os FCPs foram prorrogados por tempo indeterminado pela Emenda Constitucional n $\mathrm{n}^{\circ}$ 67, de 22 de dezembro de 2010. No âmbito estadual, estados (e Distrito Federal) foram autorizados a criar um adicional de até $2 \%$ na alíquota do Imposto sobre Operações Relativas à Circulação de Mercadorias e sobre Prestações de Serviços de Transportes Interestadual e Intermunicipal e de Comunicação (ICMS) sobre os produtos e serviços supérfluos para compor os respectivos fundos. No estado do Ceará, o FECOP foi instituído pela Lei Complementar $n^{\circ} 37$, de 26 de novembro de 2003, e regulamentado pelo Decreto $\mathrm{n}^{\circ} 29.910$, de 29 de setembro de 2009. No âmbito do governo do estado do Ceará, o FECOP atua como um instrumento complementar às políticas públicas financiando programas e projetos de combate à pobreza (Ceará, 2014). ${ }^{1}$

Dados da Pesquisa Nacional por Amostra de Domicílios, vinculada ao Instituto Brasileiro de Geografia e Estatística (PNAD/IBGE), apresentados por Miro e Barros (2018), mostram que, entre os estados da região Nordeste, identificada e reconhecida como a região mais pobre do país, o Ceará foi uma das unidades da federação que mais avançaram na redução da quantidade de pessoas vivendo em situação de pobreza. Adotando uma linha de pobreza baseada em necessidades básicas, a proporção de pobres no estado foi reduzida em quase 30 pontos percentuais, de aproximadamente $48 \%$ em 2004, para 19,3\% em $2014 .{ }^{2}$ Em números absolutos, em 2004 havia mais de 3,8 milhões de pessoas em condição de pobreza no estado e em 2014 esse número foi de aproximadamente 1,7 milhões de pessoas. ${ }^{3}$

Alguns trabalhos na literatura, tais como, Teixeira (2008), Muniz (2010) e Filgueiras (2010), buscaram avaliar o efeito dessa política sobre diversos indicadores; porém, não foi encontrado um estudo que tenha verificado o impacto direto da criação desse fundo sobre a redução da pobreza e da

1 O montante de recursos corresponde ao adicional de dois pontos percentuais na alíquota do ICMS. Mais detalhes podem ser consultados em CEARÁ (2014).

2 A linha de pobreza adotada foi calculada pelo Instituto do Trabalho e Sociedade (IETS). Disponível em: <https://www.iets.org.br/>.

3 Dados mais recentes, tabulados e apresentados pelo IPECE, mostram que a redução na proporção de pessoas pobres apresentou pequena inversão em 2015 , associada à recessão da economia brasileira em 2015 e 2016. Para mais detalhes, ver IPECE (2017). 
extrema pobreza. Com isso, este trabalho visa contribuir com a literatura ao responder o seguinte questionamento: a criação do FECOP, em 2003, contribui para a redução da pobreza no estado do Ceará?

Nesse sentido, o presente estudo tem como objetivo apresentar uma avaliação de impacto do Fundo Estadual de Combate à Pobreza do Ceará (FECOP/CE) sobre a trajetória de indicadores de pobreza e extrema pobreza do estado. Pretende-se avaliar o impacto da constituição do FECOP e, consequentemente, das estratégias financiadas por ele, sobre indicadores de pobreza em nível estadual. Para tanto, será aplicado o Controle Sintético Generalizado, uma metodologia recentemente desenvolvida por $\mathrm{Xu}$ (2017) e ainda não aplicada no Brasil, em que se propõe unificar o método de controle sintético proposto por Abadie et al. (2010) com modelos lineares de efeitos fixos. Por fim, será feito um comparativo entre o Ceará e os estados utilizados na simulação do controle sintético no que se refere ao Bolsa Família, a fim de verificar se o efeito encontrado por este trabalho pode estar sendo afetado por essa outra política.

A constituição de Fundos de Combate à Pobreza em âmbito estadual, em acordo com a Emenda Constitucional n ${ }^{\circ}$ 31, de 14 de dezembro de 2000, estabelece um mecanismo válido para o financiamento de estratégias ajustadas à realidade de cada unidade federativa. Espera-se, com a elaboração do presente artigo, fomentar as discussões a respeito de políticas de combate à pobreza no Brasil em âmbito regional e destacar a importância de instrumentos de avaliação dessas políticas.

Com essa proposta, o artigo está organizado em seis seções, além desta introdução. Na primeira delas faz-se uma breve revisão de literatura sobre os principais estudos da pobreza no Brasil. Na seção 3, apresenta-se uma descrição do FECOP/CE e da literatura empírica acerca da atuação dos Fundos de Combate à Pobreza no Brasil, com ênfase no FECOP cearense. Na seção 4, apresenta-se a metodologia econométrica de Controle Sintético Generalizado e a base de dados utilizada. Os resultados da estimação são apresentados na quinta seção, enquanto a sexta apresenta um comparativo entre o Ceará e os estados utilizados na formatação do controle sintético no que se refere ao Bolsa Família. Por fim, são apresentadas as principais conclusões obtidas no estudo. 


\section{Principais estudos nacionais sobre a pobreza}

A Constituição Federal de 1988 (CF/88) é referência na implementação do bem-estar social no Brasil. Em seu artigo 194, o referido documento define seguridade social como "um conjunto integrado de ações de iniciativa dos poderes públicos e da sociedade, destinadas a assegurar os direitos relativos à saúde, à previdência e à assistência social". Nesse sentido, o Estado é responsável, por exemplo, pela promoção de políticas de erradicação da pobreza, bem como proporcionar oportunidades para a população mais vulnerável.

Conforme dados apresentados por Campos (2015), os níveis de pobreza no Brasil se mantiveram estáveis entre 1995 e 2003. A partir daí, verificou-se uma queda gradual nesses números até 2012. A taxa de pobreza foi de $35,8 \%$, em 2003 , para $15,9 \%$, em 2012; já a extrema pobreza foi de $15,2 \%$ para $5,3 \%$, respectivamente. $\bigcirc$ autor destaca que isso se deve, em parte, ao aumento na renda do trabalho e às transferências previdenciárias e sociais.

Indo ao encontro da importância do Estado no enfrentamento da pobreza, Dias et al. (2016) mostram, por meio de modelo econométrico, que o Banco Mundial priorizou o repasse de recursos ao setor referente à administração pública, em detrimento de educação e saúde nos países da América Latina e Caribe no período de 1985 a 2010. Conforme salientado pelos autores, esse resultado está de acordo com o relatório publicado em 2013 pelo Banco Mundial acerca da luta contra a extrema pobreza No referido texto, é enfatizada a importância de se reformar as instituições, a fim de proporcionar melhor acesso ao mercado, contribuindo para um desenvolvimento econômico e social mais elevado. Em outras palavras, instituições fortes podem melhorar a efetividade dos recursos públicos.

Oliveira e Jacinto (2015) verificaram se o crescimento na renda dos estados brasileiros foi pró-pobre, isto é, situação com crescimento maior na renda dos mais pobres em relação aos mais ricos. A metodologia utilizada foi proposta por Duclos (2009), na qual considera diferentes linhas de pobreza. Os dados foram extraídos da PNAD para os dois subperíodos: $1995-$ 2003 e 2003-2011. Entre os principais resultados obtidos, evidenciou-se um aumento no bem-estar da população pobre em todo o período amostral, principalmente no segundo período analisado. Os autores levantam diferentes possibilidades de explicação para esses resultados, tais como a 
"inclusão de pessoas pobres via mercado de trabalho, a expansão dos programas de transferência de renda com o objetivo de combater a pobreza e a miséria e também os aumentos reais do salário mínimo".

Nesse mesmo sentido, Carneiro, Bagolin e Tai (2016) analisaram o impacto da desigualdade e do crescimento da renda na pobreza para as regiões metropolitanas brasileiras entre 1995 e 2009. Utilizando dados da PNAD, implementaram a técnica da decomposição de Shapley, desenvolvida por Shorrocks (1999), e a mensuração dos índices de pobreza teve como base a linha de pobreza de $\mathrm{R} \$ 140$. Os resultados indicaram aumento nos indicadores de pobreza entre 1995 e 2003 em quase todas as localidades analisadas, sendo que estes passam a decair a partir de 2004. Um resultado de destaque foi o componente crescimento da renda como principal fonte de explicação para a variação nos níveis de pobreza depois de 2003.

No contexto dos municípios cearenses, Assis, Medeiros e Nogueira (2017) analisaram a relação entre pobreza extrema, crescimento e desigualdade, por meio da metodologia proposta por Bourguignon (2004). A base de dados foi obtida do Atlas do Desenvolvimento Humano no Brasil compreendo os seguintes anos: 1991, 2000 e 2010. O critério para a seleção das pessoas que se encontravam na condição de extrema pobreza foi a renda domiciliar per capita de até $\mathrm{R} \$ 70,00$ mensais, em reais de agosto de 2010. Observou-se diminuição nas taxas de pobreza extrema no Ceará no período analisado. Esse contingente passou de $39,76 \%$, em 1991, para $28,11 \%$, no ano 2000 , e $14,69 \%$, em 2010 . Os resultados indicam que as elasticidades renda da pobreza extrema foram negativas, de forma que aumentos na renda domiciliar per capita geram redução no número de indigentes. Por sua vez, a elasticidade desigualdade foi positiva; logo, municípios mais desiguais têm maior contingente de extremamente pobres.

Em um estudo para o Brasil, Rocha (2019) teve propósito tríplice ao abordar a pobreza e extrema pobreza em seus aspectos de mensuração, variação espacial, faixas de idade e desigualdade. Utilizando dados das PNADs no período de 1990 a 2015, constatou que a queda da pobreza a partir de 2004 foi seguida pelo aumento da desigualdade regional e etária. A autora destaca que as regiões Norte e Nordeste foram as mais afetadas pela pobreza, e para a última as crianças foram as mais atingidas.

Torres et al. (2011) buscaram identificar a distribuição espacial da pobreza rural na Bacia do Rio São Francisco (BRSF), utilizando dados da Pesquisa de Orçamentos Familiares - POF 2002/2003 e do Censo de 2000. Entre as 
metodologias adotadas, estão: a construção de mapas de pobreza, o cálculo do índice de autocorrelação espacial de Moran para a pobreza rural e o uso de análise de agrupamento para identificar "pontos quentes" e "pontos frios" de pobreza rural. Os autores observaram que, em algumas regiões analisadas, a pobreza rural é espacialmente autocorrelacionada. Ou seja, municípios com renda mais baixa tendem a se localizar perto de municípios com renda mais baixa.

Por sua vez, Ferreira-Batista e Cacciamali (2012) analisaram, no estado de São Paulo, o efeito da condição de migração dos pais sobre as chances dos filhos, entre 10 e 14 anos, de trabalhar e estudar. Utilizando dados censitários de 2010 e a metodologia de Oaxaca, verificaram que os filhos de casais que haviam migrado recentemente têm maiores chances de trabalhar, contribuindo para a transmissão da pobreza entre as gerações.

Utilizando dados da PNAD 2009, Ribeiro e Marinho (2015) construíram uma medida bidimensional com base na renda e na alocação de tempo para analisar a pobreza das famílias brasileiras. Com o uso do método de Vickery (1977), no qual as curvas de isoquanta da pobreza são elaboradas para diferentes arranjos familiares, perceberam uma elevação significativa nas medidas de pobreza quando o tempo é considerado um recurso. Isso porque pais que trabalham, em especial aqueles de famílias uniparentais, geralmente não possuem tempo hábil para os afazeres domésticos básicos.

\section{Fundos estaduais de erradicação da pobreza}

\subsection{0 fundo de combate à pobreza do estado do Ceará}

No Ceará, o Fundo Estadual de Combate à Pobreza (FECOP) foi criado por meio da Lei Complementar n ${ }^{\circ} 37$, de 26 de novembro de 2011/2003 (DOE de 27/11/2003), e regimentado pelo Decreto $n^{\circ} 29.910$, de 29 de setembro de 2009 (DOE de 30/09/2009). Seu propósito visa dar suporte para que as pessoas na situação de pobreza e extrema pobreza do estado possuam condições dignas de subsistência. Conforme o artigo $1^{\circ}$, Lei Complemen$\operatorname{tar} n^{\circ} 37$, o Fundo dispõe de recursos aplicados em áreas estratégicas relacionadas à educação, moradia, nutrição, saúde, saneamento básico, auxílio da renda familiar, luta contra a seca, e outros programas sociais que objetivam um padrão de vida melhor. 
A referida Lei Complementar estabelece que, entre as fontes de recursos do fundo, este dispõe de um aditivo de $2 \%$ na alíquota do ICMS, ou do imposto que vier a sobrepô-lo, o qual recai sobre os seguintes produtos e serviços: bebidas alcoólicas, armas e munições, embarcações esportivas, fumo, cigarros, aviões ultraleves e asas-deltas, energia elétrica, gasolina e serviços de comunicação.

O público-alvo constitui-se por grupos ou famílias com privação elevada nos elementos básicos para uma vida digna, por exemplo, alimentação, habitação e vestuário. A constatação da situação de pobreza é feita por meio das seguintes comprovações: a) conta de energia elétrica cujo gasto seja de até $80 \mathrm{kwh}$ por mês; b) conta de água cujo consumo seja de até $10 \mathrm{~m}^{3}$ por mês; c) documento de inscrição em auxílios assistenciais do Governo Federal; d) comprovante de recebimento de renda mensal abaixo de meio salário mínimo.

O FECOP é operacionalizado por meio de projetos agrupados em diversos programas, que atuam em duas direções. Os Programas Assistenciais são responsáveis por intervenções rápidas na pobreza com a finalidade de proporcionar uma qualidade de vida melhor para as pessoas que vivem com renda mensal inferior a meio salário mínimo. Por sua vez, os Programas Estruturantes objetivam propiciar mudanças estruturais para que os pobres tenham condições de migrar para a condição de não pobres. Estes buscam viabilizar o acúmulo de capital físico, humano e social por parte da população desprovida.

Esse fundo é gerido pelos seguintes órgãos institucionais fundamentados da Administração Pública do Estado: o Conselho Consultivo de Políticas de Inclusão Social - (CCPIS), a Coordenadoria de Promoção de Políticas de Combate à Pobreza e Inclusão Social (CCOPI), a Gerência Executiva do FECOP (GEF) - gestão administrativa -, a Secretaria da Fazenda (SEFAZ), as Secretarias Estaduais e os Parceiros Locais - gestão operacional.

O CCPIS é a instância máxima de decisão, tendo como uma de suas funções a apreciação dos projetos que pleiteiem recursos oriundos do Fundo. Os projetos aprovados são operacionalizados pelas Secretarias de Estado competentes, em que estas recebem recursos financeiros da Secretaria da Fazenda. Ademais, o CCPIS é responsável pela formulação das diretrizes que orientam as aplicações de recursos do FECOP e pela avaliação anual do desempenho das ações desenvolvidas. 
A CCOPI preza pela efetividade das ações desempenhadas; enquanto a Gerência Executiva orienta, coordena e supervisiona as ações desenvolvidas pelas Secretarias de Estado, no que se refere ao FECOP. As Secretarias Estaduais executam os projetos, tendo como função auxiliar a parte técnica e operar as ações financiadas pelo Fundo. Os Parceiros Locais são corresponsáveis na realização dos projetos, sendo representados pelo poder público do município, entidades não governamentais, empresas privadas e comunidades locais.

Conforme o Decreto ${ }^{\circ} 29.910$, de 29 de setembro de 2009, a Gerência Executiva do FECOP (GEF), junto com o Instituto de Pesquisa e Estratégia Econômica do Ceará (IPECE), sendo esta aprovada pelo Conselho Consultivo de Políticas de Inclusão Social (CCPIS), é responsável pelas avaliações anuais de performance física e financeira dos projetos financiados, além da execução do Sistema de Monitoramento e Avaliação do Fundo.

A Portaria n ${ }^{\circ} 13 / 2018$, publicada no Diário Oficial do Estado do Ceará (DOE) de 09 de março de 2018, gera o Centro de Análise de Dados e Avaliação de Políticas Públicas (CAPP), do IPECE, tendo como propósito traçar, monitorar e avaliar programas e políticas públicas no âmbito do governo estadual do Ceará. O Centro tem como principais funções avaliar os efeitos socioeconômicos das políticas públicas e de performance de gestão por resultados.

Consoante o Decreto $n^{\circ} 33.320$, de 24 de outubro de 2019, os projetos enviados à Gerência Executiva do FECOP (GEF) devem seguir as orientações do CAPP-IPECE, sendo este o órgão responsável por fazer uma avaliação antecipada de cada um dos projetos, considerando fatores importantes que devem compor o desenho e a gestão do projeto conforme os critérios estabelecidos no referido decreto.

Adicionalmente, os beneficiários dos projetos de assistência à família, estruturantes ou assistenciais, devem ser inseridos no Sistema de Cadastramento de Beneficiários e Monitoramento de Indicadores de Resultados, renomeado como Sistema de Acompanhamento de Beneficiários (SABE), criado pelo IPECE. Tal sistema é uma plataforma de software web que tem como proposta ser uma rede de informações estatísticas e geográficas direcionadas a pesquisa e capaz de monitorar e avaliar os projetos e beneficiários do FECOP, auxiliando na tomada de decisão por parte do governo do estado do Ceará.

Em relação às demais experiências nacionais no debate da análise das políticas públicas, destaca-se como precursor o Sistema de Monitoramen- 
to e Avaliação de Políticas Públicas (SiMAPP), do Instituto Jones dos Santos (IJS), sendo este estabelecido pela Lei n ${ }^{\circ} 10.744$, de 5 de outubro de 2017, do Estado do Espírito Santo. A finalidade é tornar o gasto público eficiente e aperfeiçoar as políticas públicas na esfera estadual, na medida em que contribui para a transparência e qualidade da gestão pública.

O sistema supracitado é constituído pela Comissão de Análise Estratégica (CAE), pelo Núcleo de Monitoramento e Avaliação de Política Públicas (NuMA) e pelos Órgãos Finalísticos.

A CAE seleciona anualmente as políticas a serem monitoradas e avaliadas no âmbito do poder público, conforme o Plano Plurianual do governo estadual. $\mathrm{O}$ NuMA coordena e executa o monitoramento e a avaliação das políticas públicas previstas no Plano Estadual de Monitoramento e Avaliação. Os Órgãos Finalísticos definem as medidas essenciais para o aprimoramento dos resultados das políticas monitoradas e avaliadas em cada período.

A Figura 1, a seguir, mostra que, em termos reais, o volume de recursos aplicados no FECOP do Ceará aumentou mais de 180\% entre 2004 e 2019.

Figura 1 Volume de recursos aplicados no Fundo Estadual de Combate à Pobreza do Ceará

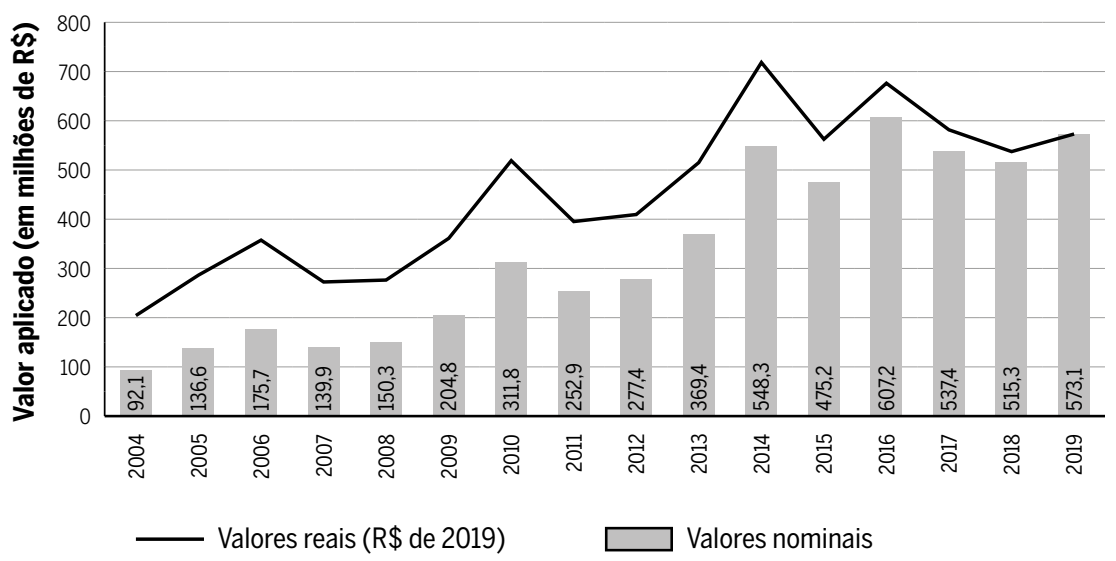

Fonte: Secretaria do Planejamento/Governo do estado do Ceará.

Nas esferas federal, estadual e municipal, Fundos de Combate e Erradicação da Pobreza foram concebidos a partir da Emenda Constitucional n ${ }^{\circ} 31$, de 14 de dezembro de 2000, que alterou o Ato das Disposições Constitucionais Transitórias (ADCT) da Constituição Federal de 1988. Conforme 
disposto no art. 82 do ADCT da Constituição Federal, estados e Distrito Federal são autorizados a criar um adicional de até $2 \%$ na alíquota do ICMS sobre os produtos e serviços supérfluos para compor os respectivos Fundos.

De forma sistematizada, o Quadro 1 apresenta a relação dos estados que aderiram ao Fundo de Combate à Pobreza (FCP) e a legislação responsável pela implementação.

Quadro 1 Estados e respectivas legislações estaduais

\begin{tabular}{|c|c|}
\hline Estado & FCP - Legislação - Criação/Vigência \\
\hline Alagoas & Lei Estadual nº 6.558 (2004); Vigência a partir de 2005. \\
\hline Bahia & $\begin{array}{l}\text { Lei Estadual nº } 12.523 \text { (2003); Decreto n } 26.402 \text {; Alteração pela } \\
\text { Lei } n^{0} 13.461 \text { (2015); Vigência a partir de } 2004 \text {. }\end{array}$ \\
\hline Ceará & $\begin{array}{l}\text { Decreto nº } 27.317 \text { (2003), alteração via Decreto n } 31.860 \text { (2015), } \\
\text { alteração via Decreto nº } 31.894 \text { (2016); Vigência a partir de } 2003 .\end{array}$ \\
\hline Maranhão & $\begin{array}{l}\text { Lei Estadual nº } 8.205 \text { (2004), alteração via Lei n } 10.329 \text { (2015); } \\
\text { Vigência a partir de } 2005 .\end{array}$ \\
\hline Paraíba & $\begin{array}{l}\text { Lei Estadual nº } 7.611 \text { (2004), alteração via Lei Estadual nº } 10.507 \text { (2015); } \\
\text { Vigência a partir de } 2005 .\end{array}$ \\
\hline Pernambuco & Lei nº 12.523 (2003); Vigência desde 2003. \\
\hline Piauí & Lei nº 5.622 (2006); Vigência desde 2006. \\
\hline Rio Grande do Norte & Lei ñ 261 (2003); Vigência desde 2004. \\
\hline Sergipe & Lei nº 4.731 (2002); Vigência desde 2003. \\
\hline Amazonas & $\begin{array}{l}\text { Lei n } 3.584 \text { - Fundo de Promoção Social (2010). } \\
\text { Lei nº } 4.457 \text { - Fundo de Promoção Social e Erradicação da Pobreza (2017). }\end{array}$ \\
\hline Rondônia & Lei nº 842 (2015); Vigência desde 2016. \\
\hline Tocantins & Lei n 3.015 (2015); Vigência desde 2016. \\
\hline Distrito Federal & Lei no 4.220 (2008); Vigência desde 2008. \\
\hline Espírito Santo & Lei Complementar nº 336 (2005); Vigência desde 2005. \\
\hline Goiás & $\begin{array}{l}\text { Lei no }^{0} 14.469 \text { (2003); regulamentado pelo Decreto nº } 5832 \text { (2003); } \\
\text { Vigência desde 2003. }\end{array}$ \\
\hline Mato Grosso & Lei nº 144 (2003); Vigência desde 2003. \\
\hline Mato Grosso do Sul & Lei nº 3.337 (2006); Vigência desde 2007. \\
\hline Minas Gerais & Lei nº 19.978 (2011); Vigência desde 2012. \\
\hline Paraná & Lei nº 18.573 (2015); Vigência desde 2015. \\
\hline Rio de Janeiro & Lei nº 4.056 (2002); Vigência desde 2003. \\
\hline Rio Grande do Sul & Lei nº 14.742 (2015); Vigência desde 2015. \\
\hline São Paulo & Lei nº 16.006 (2015); Vigência desde 2016. \\
\hline
\end{tabular}

Fonte: Elaboração propria. 


\subsection{Evidências empíricas da atuação do FECOP no Brasil}

Com o intuito de tornar as políticas públicas mais eficientes na erradicação da pobreza, Nogueira e Forte (2016) analisaram como estas podem influenciar a priorização das intervenções nos municípios do Ceará. Os dados foram extraídos do Atlas do Desenvolvimento Humano no Brasil para 1991, 2000 e 2010. Os autores estimaram as elasticidades renda e desigualdade da pobreza, considerando a linha de pobreza do Fecop, a partir das seguintes variáveis socioeconômicas: proporção de pobres, renda per capita média e índice de Gini.

Os resultados revelaram a importância das particularidades e potencialidades de cada município para se obter maior eficácia na priorização das intervenções avaliadas. $\bigcirc$ trabalho também sugere um custo de oportunidade entre eficácia e equidade nas políticas em questão. Isso porque tende a eleger os municípios em pior situação relativa, considerando o princípio da equidade. No entanto, esses locais podem apresentar um potencial de redução da pobreza mais limitado, dadas as políticas implementadas. Destacam a relevância do monitoramento e da avaliação, na medida em que contribuem para uma alocação de recursos mais eficiente e eficaz, além de auxiliar no enfrentamento dos problemas de execução.

Neves (2013) conduziu uma pesquisa exploratória utilizando dados sobre receitas e despesas coletados dos seguintes órgãos: Secretaria de Estado do Planejamento e das Finanças (SEPLAN-RN), portal de transparência e secretarias do Estado. Com a finalidade de verificar a atuação do FECOP na redução da pobreza do estado no período de 2009 a 2012, mediante análise vertical e horizontal, observou que os recursos do Programa têm sido aplicados conforme prescreve a $\mathrm{CF} / 88$, nomeadamente em quatro programas: Nutrição e segurança alimentar, Aquisição e distribuição de leite, Habitação para baixa renda e Assistência Técnica ao Agronegócio Agricultura Familiar.

Em uma pesquisa cearense sobre o mapeamento da pobreza e a distribuição dos recursos do FECOP e do Programa Bolsa Família (PBF) para o ano de 2010, Melo Filho (2012) utilizou dados municipais abrangendo várias bases de dados: Secretaria de Estado de Planejamento e Gestão (SEPLAG), IBGE, IPECE e IPEADATA (Base de dados do Instituto de Pesquisa Econômica Aplicada). A metodologia adotada se baseou na elaboração de índices municipais desses programas citados e nas estatísticas sobre como 
esses recursos estão distribuídos de forma eficiente. Os principais resultados revelaram que, em relação aos indicadores de cobertura municipal, a alocação regional dos recursos do FECOP ocorre de forma mais dispersa, enquanto o PBF é mais eficiente na distribuição dos seus recursos. Todavia, ao serem incluídas variáveis de controle (efeito populacional, influência política e impacto econômico), ambos os programas demonstraram eficiência.

Por outro lado, Muniz (2010) verificou a atuação do FECOP para o desenvolvimento do Ceará no período de 2004 a 2006, medida pelo Índice de Desenvolvimento Municipal (IDM). Por meio da análise de correlação, foi demostrado que o referido fundo, junto com o Programa Bolsa Família, contribuiu para o aumento do IDM médio dos municípios analisados, considerando as transferências em termos absolutos. No período analisado, o FECOP apresentou um desempenho econômico-financeiro positivo.

Utilizando informações do CadÚnico (Cadastro Único para Programas Sociais do Governo Federal) para o Ceará em 2007, Filgueiras (2010) descreveu as ações realizadas pelo FECOP para investigar a pobreza, ao mensurar e estruturar as deficiências características de cada município, através do cálculo do Índice de Desenvolvimento da Família (IDF), sendo este constituído por seis medidas (inexistência de vulnerabilidade, aquisição de conhecimento, obtenção de recursos disponíveis, desenvolvimento infantil, acessibilidade ao trabalho e condições de moradia), 22 componentes e 41 indicadores. Os resultados do Ceará ficaram abaixo no que diz respeito ao Brasil, mas superiores aos da região Nordeste. Em relação às dimensões analisadas, o acesso ao trabalho, a disponibilidade de recursos e o conhecimento acessível apresentaram um cenário preocupante, enquanto a vulnerabilidade familiar, as condições de moradia e o desenvolvimento infantil demonstraram resultados satisfatórios.

A fim de analisar os efeitos do FECOP nos municípios do Ceará com destaque na educação, Teixeira (2008) utilizou dois modelos Probit, sendo que um mede o impacto da gestão do município que obteve recursos do Fundo - com a construção do Índice Sintético do Esforço de Gestão (ISG) - e o outro avalia o desempenho dos resultados - com a criação do Índice Sintético do Esforço de Desempenho (ISD). Ambos correspondem à média aritmética para o período anterior (2001/2002) e posterior (2004/2005) à criação do FECOP. Os resultados do primeiro modelo referente à gestão indicam que os municípios beneficiados com recursos do FECOP não se 
diferenciam daqueles que não o são em relação ao esforço de gestão. Além disso, a oferta de serviços educacionais não explica a condição de beneficiário ou não de programas de educação financiados pelo FECOP. Por sua vez, o modelo sobre desempenho evidenciou que o patamar inicial de desempenho educacional afetou positivamente a condição de beneficiário de programas educacionais. Ademais, os municípios contemplados pelo FECOP têm maior evolução do desempenho em relação aos outros. Em ambos os modelos, as chances de o município receber recursos do FECOP são reduzidas em função da dimensão econômica.

\section{Metodologia}

\subsection{0 método de Controle Sintético Generalizado}

Uma opção metodológica para a estimação do efeito causal dos fundos estaduais de combate à pobreza é a aplicação de modelos de efeitos fixos (Diferença-em-Diferença). Conforme argumenta Xu (2017), uma das hipóteses do método de Diferenças-em-Diferenças é que as variáveis de resultados das unidades tratadas e não tratadas seguem trajetórias paralelas em um cenário na ausência da intervenção. No entanto, em diversas situações, os dados não possuem um pareamento das tendências observadas em períodos anteriores à intervenção, entre os grupos de tratamento e de controle. A ausência dessa condição faz com que o método de Diferenças-em-Diferenças não seja eficiente para a estimação dos efeitos de uma intervenção no período de pós-tratamento. Uma das principais causas para a falha da hipótese de paralelismo das tendências é a presença de variáveis de confusão não observáveis ao longo do tempo (Xu, 2017).

$\mathrm{O}$ procedimento do Controle Sintético Generalizado proposto por $\mathrm{Xu}$ (2017) constrói contrafactuais para cada unidade tratada usando informações de um grupo de controle a partir de um modelo de efeitos fixos com interceptos para cada unidade e interações com coeficientes variáveis no tempo. Essa abordagem busca unificar o método de controle sintético proposto por Abadie et al. (2010) com modelos lineares de efeitos fixos interativos, como proposto por Bai (2009), obtendo uma estrutura simples, da 
qual o método de Diferenças-em-Diferenças é um caso especial. ${ }^{4}$

Consideram-se as observações dispostas em um painel balanceado que apresentam um conjunto de resultados $Y_{i t}$ para cada unidade $i \in\{1, \ldots, N\}$ no tempo $t \in\left\{1, \ldots, T_{0}, T_{0}+1, \ldots, T\right\}$. Supõe-se que a intervenção ocorre em $T_{0}+1$, tal que $t=1,2, \ldots, T_{0}$ são períodos anteriores à intervenção e à pré-intervenção. E que $T_{0}+1, \ldots, T$ são os períodos pós-intervenção. Das unidades observadas, denota-se por $\tau$ o grupo ou unidade tratada, e por $C$, o conjunto de unidades de controle. Se o número de unidades de tratamento é $N_{T}$ e de controle é $N_{C}$, tem-se que $N=N_{T}+N_{C}$.

Por suposição, o modelo adotado assume a seguinte forma funcional:

$$
Y_{i t}=\delta_{i t} D_{i t}+X_{i t}^{\prime} \beta+\lambda_{i}^{\prime} f_{t}+\varepsilon_{i t}
$$

Nessa expressão, $D_{i t}$ é o indicador de tratamento, sendo $D_{i t}=1$ se a unidade recebe a intervenção, ou seja, quando $i \in \tau$ e $t>T_{0}$, e $D_{i t}=0$, caso contrário. $O$ termo $\delta_{i t}$ representa o efeito do tratamento para a unidade $i$ ao período $t$; $X_{i t}$ é um vetor $(k \times 1)$ de variáveis explicativas observáveis, $\beta=\left[\beta_{1}, \ldots, \beta_{k}\right]^{\prime}$ é um vetor $(k \times 1)$ de parâmetros desconhecidos, $f_{t}=\left[f_{1 t}, \ldots, f_{r t}\right]^{\prime}$ é um vetor $(r \times 1)$ de fatores comuns não observáveis e $\lambda_{i}=\left[\lambda_{1 t}, \ldots, \lambda_{r t}\right]^{\prime}$ é um vetor de cargas fatoriais desconhecidas. Por fim, $\varepsilon_{i t}$ representa choques idiossincráticos não observáveis para cada unidade $i$ e tempo $t$, tendo $E\left(\varepsilon_{i t}\right)=0$. Uma suposição importante para essa forma funcional é que todas as unidades estão sujeitas ao mesmo conjunto de fatores, de número fixo, durante o período observado, ou seja, essa forma funcional não admite quebras estruturais.

Usando a notação de resultados potenciais, o efeito individual do tratamento sobre uma unidade tratada $i$ no tempo $t$ é

$$
\delta_{i t}=Y_{i t}(1)-Y_{i t}(0)
$$

4 O Método de Controle Sintético Generalizado proposto por Abadie et al. $(2010,2015)$ busca balancear a influência de variáveis de confusão através da construção de uma unidade de controle sintética construída a partir da ponderação das unidades não tratadas disponíveis, que é adotada como possível contrafactual para a unidade de tratamento. Já o modelo com efeitos fixos interativos proposto por Bai (2009) incorpora interceptos específicos da unidade, denotadas cargas fatoriais, interagindo com coeficientes variáveis no tempo, referidos como fatores (latentes), como forma de corrigir possiveis heterogeneidades temporais não observadas. 
Com $i \in \tau$ e $t \in T_{0}+1, T_{0}+2, \ldots, T, Y_{i t}(1)$ representa o resultado de $i$ sob o tratado, e $Y_{i t}(0)$ refere-se ao contrafactual do resultado dessa mesma unidade, em um cenário sem a intervenção.

Para cada unidade de controle, o processo gerador de dados assume a seguinte forma:

$Y_{i}=X_{i}^{\prime} \beta+F \lambda_{i}+\varepsilon_{i}, \operatorname{com} i \in \mathrm{C}$. Do conjunto de unidades de controle, ao serem empilhadas, tem-se:

$$
Y_{c o}=X_{c o} \beta+F \Lambda_{c o}^{\prime}+\varepsilon_{c o}
$$

Em que $Y_{C O}=\left[Y_{1}, Y_{2}, \ldots, Y_{N_{C O}}\right]$ e $\varepsilon_{C O}=\left[\varepsilon_{1}, \varepsilon_{2}, \ldots, \varepsilon_{N_{C O}}\right]$ são matrizes $\left(T \times N_{C O}\right)$; $N_{C O}$ é uma matriz tridimensional $\left(T \times N_{C O} \times p\right)$; e $\Lambda_{C O}=\left[\lambda_{1}, \lambda_{2}, \ldots, \lambda_{N_{C O}}\right]^{\prime}$ é uma matriz $\left(N_{C O} \times r\right)$, portanto, $X_{C O} \beta$ e $F \Lambda_{C O}^{\prime}$ são matrizes $\left(T \times N_{C O}\right)$.

Seguindo Bai (2009), fatores e cargas fatoriais devem ser normalizados, $F^{\prime} F / T=I_{r}$, e ortogonais entre si, $\Lambda_{C}^{\prime} \Lambda_{C}=D$, em que $D$ é uma matriz diagonal. Por sua vez, o número de fatores é definido por meio de um algoritmo de "validação cruzada" que utiliza as informações do grupo de controle e da unidade tratada no período pré-intervenção.

O estimador de Controle Sintético Generalizado para o efeito médio do tratamento sobre os tratados ou ATT (average treatment effect on the treated) é dado pela diferença entre o resultado atual, $Y_{i t}(1)$, e o contrafactual estimado $\widehat{Y}_{i t}(0)$. O estimador do $A T T_{t}$ é:

$$
\widehat{A T T_{t}}=\frac{1}{N_{t r}} \sum_{i \in T}\left[Y_{i t}-\widehat{Y}_{i t}(0)\right] \text { para } t>T_{0}
$$

A estimação do contratual é realizada em três passos que envolvem: a) a estimação de um modelo de efeitos fixos interativos usando apenas o grupo de controle, obtendo $\left.\hat{\beta}, \hat{F}, \hat{\Lambda}_{C} ; b\right)$ a estimação de cargas fatoriais para cada unidade tratada, minimizando o erro quadrático médio do resultado esperado previsto nos períodos pré-tratamento e; c) calcular o contrafactual para os tratados com base nas estimativas.

Por fim, a inferência do modelo é realizada com a estimação da variância aplicando um procedimento de bootstrap paramétrico por meio de reamostragem dos resíduos. Detalhes a respeito do processo de estimação e da inferência do modelo podem ser vistos em Xu (2017). 


\subsection{Dados}

Com o objetivo de estimar os determinantes do indicador de pobreza, foi considerado como referencial teórico um modelo ao estilo de Bourguignon (2004), que estabelece uma relação entre pobreza, nível médio de renda e distribuição da renda.

Assim, o modelo adotado como base estabelece o indicador de proporção de pobres em função de um indicador do nível de renda (renda domiciliar per capita média) e do nível de desigualdade de renda, mensurado pelo Coeficiente de Gini. Além dessas variáveis, buscou-se inserir outras que captassem o nível educacional (escolaridade média em anos de estudo) e a situação do mercado de trabalho (taxa de desemprego), apesar de essa taxa não estar disponível para o mesmo intervalo de tempo..$^{5} \mathrm{Xu}$ (2017) afirma que, para o uso do método de controle sintético, quanto maior for o período "pré-tratamento", melhor é o desempenho do modelo no que se refere ao ajuste entre a trajetória observada e o contrafactual.

A base de dados do estudo é a Pesquisa Nacional por Amostra de Domicílios (PNAD) levada a campo anualmente pelo Instituto Brasileiro de Geografia e Estatística (IBGE). ${ }^{6}$ Foram considerados indicadores para o período de 1981 a 2014, que estão disponíveis na base do IPEADATA (http:// www.ipeadata.gov.br). No Quadro 2 tem-se uma breve descrição de cada variável e a sua representação no modelo utilizado.

Conforme informações disponíveis sobre a legislação dos fundos estaduais de combate à pobreza, o grupo de controle foi definido com base no conjunto de unidades federativas que não haviam estabelecido um Fundo Estadual de Combate à Pobreza até o ano de 2014. De acordo com esse critério, o potencial grupo de controle é então composto pelas seguintes unidades federativas: Acre, Amapá, Amazonas, Pará, Rondônia, Roraima, São Paulo, Paraná, Santa Catarina e Rio Grande do Sul. No entanto, isso não significa que tais entes federativos não adotem outras estratégias para o financiamento de políticas de combate à pobreza, assim como o Ceará possui outras formas de minimizar esse problema.

5 Disponível a partir de 1992.

6 Uma vez que a PNAD não é realizada em anos em que a pesquisa censitária vai a campo, lacunas na base de dados foram preenchidas por interpolação de valores. 
Quadro 2 Descrição de variáveis

\begin{tabular}{l|l}
\hline Variável & Descrição \\
\hline $\begin{array}{l}\text { Proporção de } \\
\text { pobres - } \text { pob }_{i t}\end{array}$ & $\begin{array}{l}\text { Percentual de pessoas na população total com renda domiciliar per capita } \\
\text { inferior à linha de pobreza. A linha de pobreza aqui considerada é o dobro da } \\
\text { linha de extrema pobreza, uma estimativa com base em recomendações da } \\
\text { Organização das Nações Unidas para a Alimentação e a Agricultura (FAO) e } \\
\text { da Organização Mundial de Saúde (OMS). }\end{array}$ \\
\hline $\begin{array}{l}\text { Coeficiente de Gini } \\
\text { para a desigualda- } \\
\text { de de renda - gini }\end{array}$ & $\begin{array}{l}\text { Mede o grau de desigualdade na distribuição da renda domiciliar per capita } \\
\text { entre os indivíduos. Seu valor pode variar teoricamente desde 0, quando } \\
\text { não } 1, \text { quando a desigualdade é máxima (apenas um indivíduo detém toda a } \\
\text { atenda da sociedade, e a renda de todos os outros indivíduos é nula). }\end{array}$ \\
\hline $\begin{array}{l}\text { Renda domiciliar } \\
\text { per capita média } \\
\text { (R\$ outubro 2014) } \\
\text { - rdpc }\end{array}$ & $\begin{array}{l}\text { Renda média mensal da população, com valores reais aos preços vigentes } \\
\text { na realização da última edição da pesquisa, atualizados conforme o deflator } \\
\text { para rendimentos da Pnad apresentado pelo IPEADATA. }\end{array}$ \\
\hline $\begin{array}{l}\text { Anos de estudo } \\
\text { média - est }\end{array}$ & $\begin{array}{l}\text { Razão entre o somatório do número de anos de estudo completados pelas } \\
\text { pessoas que têm 25 ou mais anos de idade e o número de pessoas nessa } \\
\text { faixa etária. }\end{array}$ \\
\hline
\end{tabular}

Fonte: Elaboração própria.

\section{Resultados}

\subsection{Impacto do FECOP sobre indicadores de pobreza}

Com o objetivo de avaliar o impacto do FECOP sobre os indicadores de proporção de pobres e de extremamente pobres no estado do Ceará, é fundamental a construção de um cenário contrafactual em que o Fundo não tivesse sido constituído, conforme exposto anteriormente. No contexto do problema analisado, a realização da avaliação de impacto exige a comparação da evolução das taxas de pobreza e extrema pobreza realmente observadas no período com trajetórias simuladas (contrafactuais), caso a intervenção não tivesse ocorrido.

A aplicação do método de Controle Sintético Generalizado permite a obtenção de um grupo de comparação representado por uma combinação de estados potenciais cuja evolução dos indicadores de pobreza no período pré-intervenção se aproxime daquela observada para o Ceará. A aplicação 
do método permite a obtenção de pesos para cada unidade do grupo de controle de forma a promover um bom ajuste das trajetórias no período pré-intervenção em relação à trajetória dos indicadores observados para o Ceará. Na aplicação em questão, os pesos estimados para estados do grupo de controle e que serão utilizados na construção do "Ceará sintético" são apresentados na Tabela 1.

Tabela 1 Pesos sintéticos estimados para cada unidade federativa do grupo de controle

\begin{tabular}{lrrr}
\hline UF & Pobreza & Extrema pobreza \\
\hline Rondônia & -0.375 & -0.222 \\
\hline Acre & -0.173 & 0.017 \\
\hline Amazonas & -0.558 & -0.340 \\
\hline Roraima & -0.069 & -0.110 \\
\hline Pará & 0.296 & 0.069 \\
\hline Amapá & -0.160 & -0.161 \\
\hline São Paulo & -0.345 & -0.241 \\
\hline Paraná & 0.481 & 0.160 \\
\hline Santa Catarina & -0.041 & -0.100 \\
\hline Rio Grande do Sul & -0.056 & -0.073 \\
\hline
\end{tabular}

Fonte: Estimativa dos autores, a partir dos dados da pesquisa.

Por sua vez, o principal resultado dessa avaliação é apresentado na Figura 2, que apresenta as trajetórias das taxas de pobreza e extrema pobreza para o Ceará e para os controles sintéticos de cada uma delas.

Em cada um dos gráficos da Figura a área mais clara sinaliza o período pré-tratamento, ao passo que a área escura sinaliza o período pós-tratamento, ou seja, de vigência do FECOP no estado. É possível verificar um bom ajuste entre o Ceará e o controle sintético no período pré-tratamento para cada um dos indicadores, uma vez que se tem uma sobreposição das trajetórias. No período pós-tratamento observa-se que as trajetórias passam a divergir, destacando que as trajetórias das taxas de pobreza e extrema pobreza observadas para o Ceará declinam de forma mais acentuada do que a trajetória prevista pelo controle sintético. Essa divergência é um sinal importante a favor de um impacto do FECOP sobre a redução dos indicadores de pobreza no Ceará. 
Figura 2 Trajetória das taxas de pobreza e extrema pobreza: Ceará e controle sintético

Pobreza

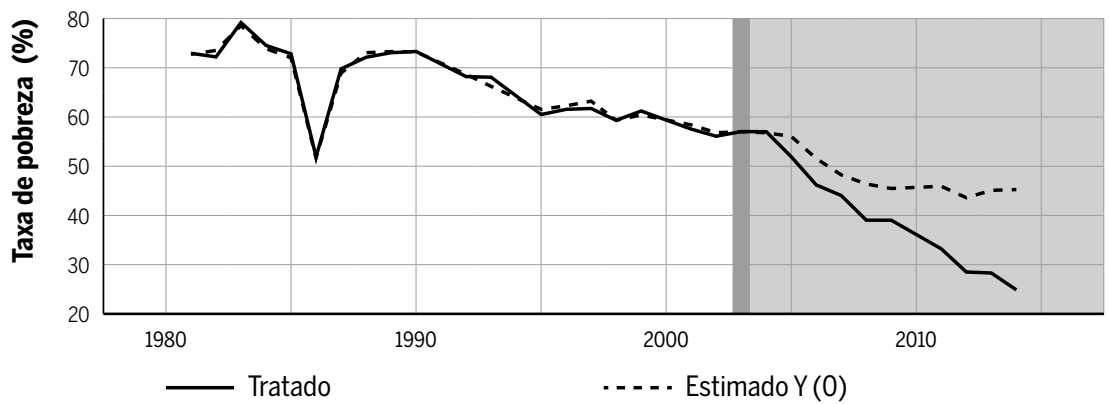

Extrema Pobreza

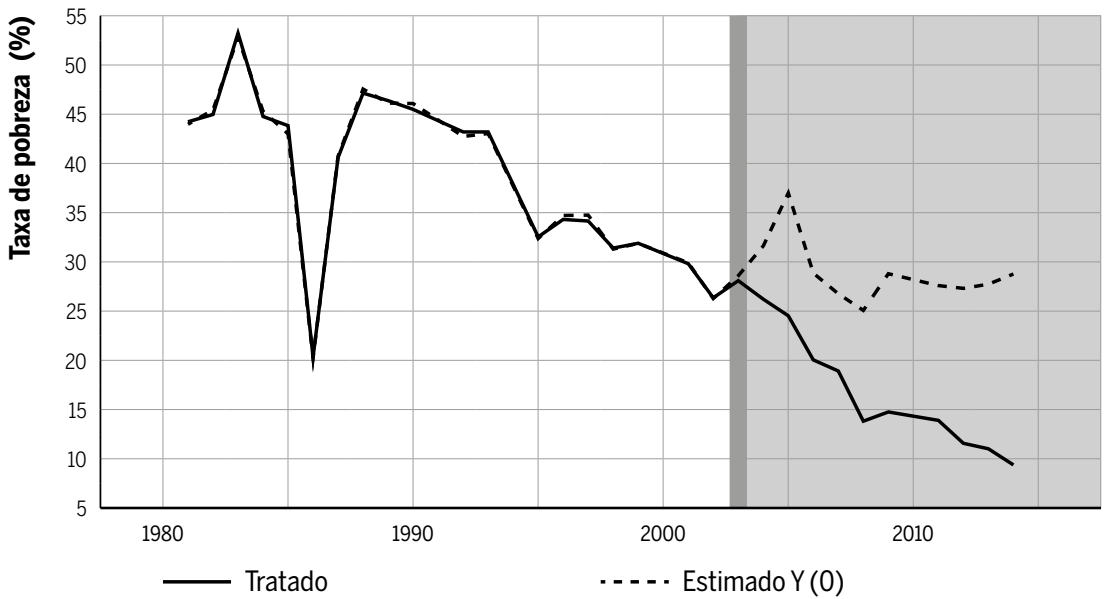

Fonte: Estimativa dos autores, a partir dos dados da pesquisa.

A evolução das taxas de pobreza entre o Ceará e o seu contrafactual começa a se distanciar alguns anos após o início da atuação do FECOP/CE no financiamento de projetos de combate à pobreza no estado.

Os resultados da Tabela 2 permitem uma análise ainda mais detalhada ao destacar a significância estatística do impacto do FECOP sobre os indicadores de pobreza do Ceará. Nessa Tabela, são apresentadas estimativas do efeito médio do tratamento sobre a unidade tratada (ATT) para os anos que se seguiram após a criação do FECOP. O Fundo passa a ter um impacto 
estatisticamente significante (nível de significância de 1\%) sobre os indicadores de pobreza no Ceará a partir de 2005.

O impacto médio do FECOP, ao longo do período analisado, foi de aproximadamente $9,26 \%$ (com desvio padrão de 0,782 ) sobre o indicador de pobreza, e de $12,66 \%$ (com desvio padrão de 0,98 ) sobre o indicador de extrema pobreza. Também é possível verificar, pelos valores do ATT de cada ano, que o impacto segue aumentando, de forma que a redução da pobreza e da pobreza extrema no Ceará se destaca cada vez mais da trajetória projetada pelo controle sintético. Com isso seria possível projetar para uma continuidade dessa tendência, com ampliação dos impactos do Fundo.

Tabela 2 Efeito médio do FECOP sobre indicadores de pobreza no Ceará

\begin{tabular}{|c|c|c|c|c|c|c|c|c|c|c|}
\hline & \multicolumn{5}{|c|}{ Taxa de pobreza } & \multicolumn{5}{|c|}{ Taxa de extrema pobreza } \\
\hline & ATT & S.E. & Cl.lower & Cl.upper & p.value & ATT & S.E. & Cl.lower & Cl.upper & p.value \\
\hline 2004 & 0.216 & 1.276 & -2.286 & 2.717 & 0.866 & -5.408 & 1.650 & -8.642 & -2.174 & 0.001 \\
\hline 2005 & -4.133 & 1.164 & -6.415 & -1.851 & 0.000 & -12.469 & 3.157 & -18.656 & -6.282 & 0.000 \\
\hline 2006 & -5.360 & 0.894 & -7.112 & -3.608 & 0.000 & -8.811 & 1.145 & -11.056 & -6.567 & 0.000 \\
\hline 2007 & -4.195 & 0.766 & -5.697 & -2.693 & 0.000 & -7.847 & 3.563 & -14.830 & -0.865 & 0.028 \\
\hline 2008 & -7.361 & 0.786 & -8.902 & -5.820 & 0.000 & -11.254 & 1.156 & -13.519 & -8.989 & 0.000 \\
\hline 2009 & -6.447 & 1.609 & -9.600 & -3.294 & 0.000 & -14.043 & 1.125 & -16.247 & -11.838 & 0.000 \\
\hline 2010 & -9.582 & 1.239 & -12.011 & -7.153 & 0.000 & -13.866 & 1.187 & -16.193 & -11.540 & 0.000 \\
\hline 2011 & -12.717 & 1.086 & -14.846 & -10.588 & 0.000 & -13.690 & 1.468 & -16.568 & -10.813 & 0.000 \\
\hline 2012 & -15.087 & 0.767 & -16.591 & -13.584 & 0.000 & -15.740 & 1.603 & -18.882 & -12.598 & 0.000 \\
\hline 2013 & -16.796 & 1.094 & -18.939 & -14.652 & 0.000 & -16.721 & 1.761 & -20.172 & -13.270 & 0.000 \\
\hline 2014 & -20.384 & 0.791 & -21.935 & -18.833 & 0.000 & -19.393 & 1.699 & -22.724 & -16.063 & 0.000 \\
\hline $\begin{array}{l}\text { Impacto } \\
\text { médio }\end{array}$ & -9.259 & 0.782 & -10.792 & -7.726 & 0.000 & -12.658 & 0.984 & -14.588 & -10.729 & 0.000 \\
\hline
\end{tabular}

Fonte: Estimativa dos autores, a partir dos dados da pesquisa.

Os gráficos da Figura 3 apresentam estimativas das diferenças nas taxas de pobreza e extrema pobreza entre o Ceará e o Controle Sintético. Eles destacam a significância estatística do efeito do FECOP sobre esses indicadores mostrando os intervalos de confiança de $95 \%$ obtidos pela aplicação do método de bootstrap, em que foram aplicadas mil replicações. 
Figura 3 Estimativa do efeito médio do FECOP sobre a taxa de pobreza no Ceará

Pobreza

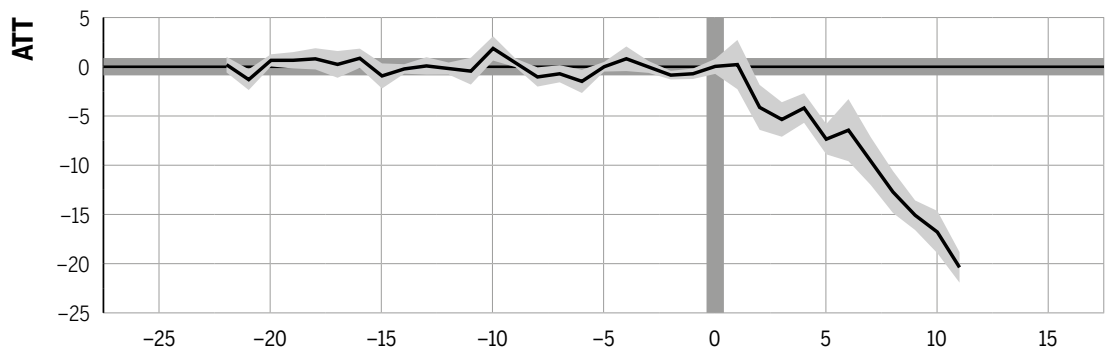

Anos em relação ao tratamento

\section{Extrema Pobreza}

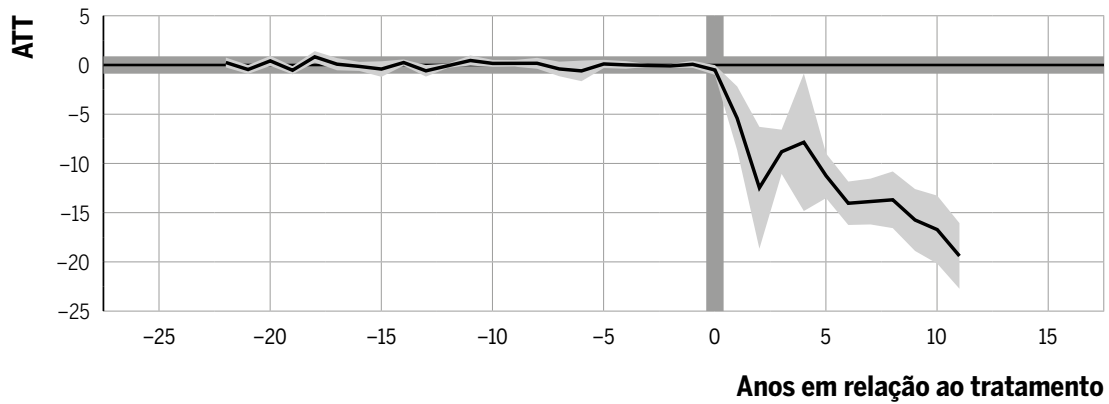

Fonte: Estimativa dos autores, a partir dos dados da pesquisa.

\subsection{Bolsa Família e estado sintético}

Além do Fundo Estadual de Combate à Pobreza, existem outros tipos de programas federais e estaduais que possuem como objetivo erradicar a pobreza e a extrema pobreza, entre eles se destaca o Programa Bolsa Família (PBF), que é um programa federal atendendo a todos os estados. O PBF foi criado pela Medida Provisória n ${ }^{\circ} 132$, em outubro de 2003, e convertida na Lei $n^{\circ}$ 10.836, em janeiro de 2004, com a unificação de programas sociais, como Bolsa Escola, Bolsa Alimentação, Auxílio Gás e Programa Nacional de Acesso à Alimentação. Trata-se de um programa de transferência de renda condicionada e representa uma das principais políticas de combate à pobreza no Brasil. 
O PBF atende famílias em condição de extrema pobreza (que declaram auferir renda per capita até $\mathrm{R} \$ 85,00$ ) e de pobreza (cuja renda per capita está entre $\mathrm{R} \$ 85,01$ e $\mathrm{R} \$ 170,00)$. Conforme apresentado pelo Ministério do Desenvolvimento Social, o Programa possui três eixos de atuação: a) complemento de renda, com o objetivo de prover alivio imediato da situação de pobreza ou extrema pobreza; b) condicionalidades, que buscam reforçar o acesso aos direitos básicos nos setores de educação, saúde e assistência social; e c) ações complementares que buscam o desenvolvimento das famílias e a superação da situação de vulnerabilidade (MDS, 2018). ${ }^{7}$

Como visto na seção anterior, o impacto médio do FECOP, ao longo do período analisado, foi de aproximadamente $8 \%$, tanto no indicador de pobreza, quanto no indicador de extrema pobreza. Para obtenção desses resultados, foi criado um estado sintético a partir dos estados pertencentes ao grupo de controle, os quais foram selecionados por meio da condição de ausência do Fundo Estadual de Combate à Pobreza até 2015, a saber: Rondônia, Acre, Amazonas, Roraima, Pará, Amapá, São Paulo, Paraná, Santa Catariana e Rio Grande do Sul; e os pesos para a formação desse estado sintético são encontrados pelo próprio método por meio das variáveis utilizadas.

Uma variável importante a ser incluída no modelo seria o total de repasse do Bolsa Família aos estados, porém não existem dados de uma série histórica longa equivalente à utilizada por este trabalho. Dessa forma, não foi possível utilizá-la, porém acredita-se que a ausência dessa variável não afete o efeito aqui encontrado, por se tratar de uma política que abrange todos os estados do Brasil, inclusive o Ceará.

Além disso, embora o valor do repasse seja heterogêneo entre os estados, existem estados pertencentes ao grupo de controle que recebem equivalentemente ou superior ao estado do Ceará. Segundo o MDS (2018), existem alguns estados que mais necessitam de recursos do programa, por possuírem uma quantidade maior de famílias de baixa renda, entre eles, Maranhão, Piauí, Acre, Paraíba, Pará, Alagoas e Amazonas. Destes, três pertencem ao grupo de controle utilizado para a criação do estado sintético.

Optou-se por fazer um comparativo do Ceará com cada estado selecionado referente ao total de recursos e ao total de beneficiários do Bolsa

7 Valores e informações obtidos no site do Ministério do Desenvolvimento Social e Combate à Fome (MDS) <http://mds.gov.br/assuntos/bolsa-familia/o-que-e/beneficios>. Acesso em: fev. 2018. 
Família, no período considerado na pesquisa, os quais estão dispostos na Figura 4.

Figura 4 Repasse do Bolsa Família - Ceará $x$ estados pertencentes ao grupo de controle

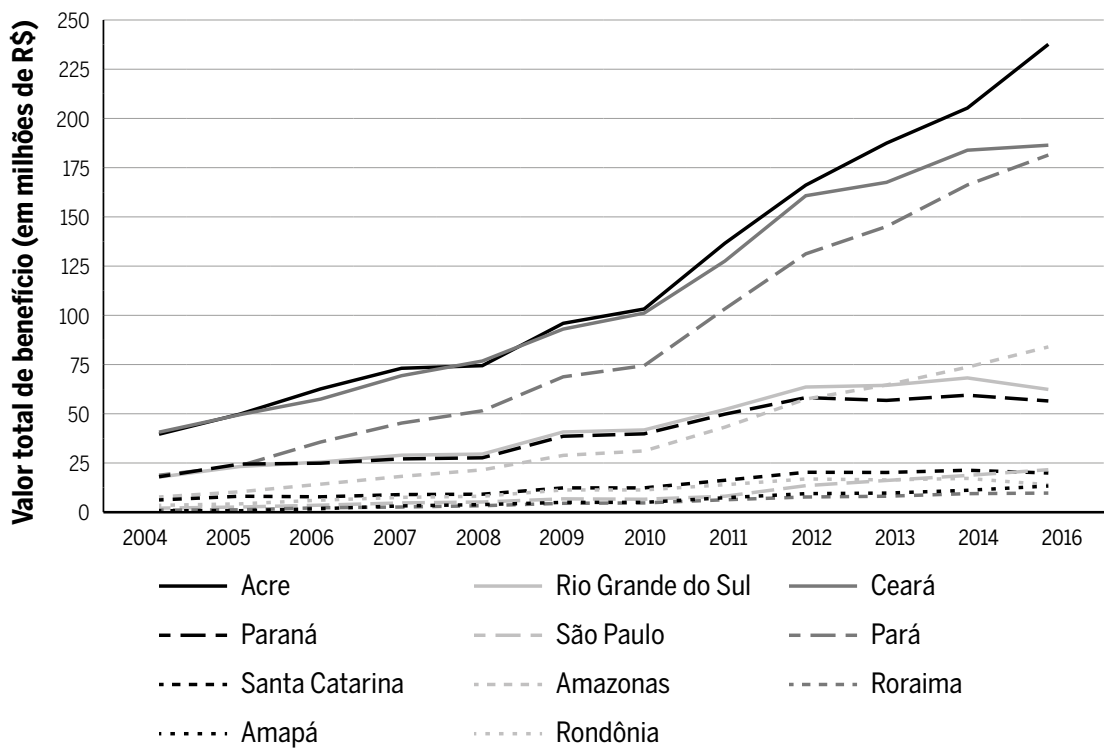

Fonte: Elaboração própria, a partir dos dados disponíveis pelo MDS.

A partir desses gráficos observa-se que existem estados no período analisado que recebem repasse semelhante e superior ao estado do Ceará, Pará e São Paulo, respectivamente. Dessa forma, acredita-se que os efeitos do FECOP encontrados por este trabalho não estejam sendo afetados pela ausência da variável que representa o repasse do Bolsa Família, uma vez que todos os estados participam do PBF e que, embora o repasse seja heterogêneo, alguns estados selecionados para o grupo de controle apresentam valor equivalente e superior ao estado do Ceará.

\section{Considerações finais}

O objetivo do presente estudo é apresentar uma avaliação de impacto do Fundo Estadual de Combate à Pobreza do Ceará (FECOP/CE) sobre a trajetória de indicadores de pobreza e extrema pobreza do estado. Para tanto, 
se faz necessária a construção de um cenário contrafactual em que o FECOP não tivesse sido constituído.

Com base em indicadores para o período de 1981 a 2014, disponíveis no IPEADATA, foram estimadas trajetórias para a pobreza e a pobreza extrema no Ceará e no grupo de controle adotado na análise. A definição desse grupo teve como base o conjunto de unidades federativas que não haviam estabelecido um Fundo Estadual de Combate à Pobreza até o ano de 2014, sendo composto, quais sejam: Acre, Amapá, Amazonas, Pará, Rondônia, Roraima, São Paulo, Paraná, Santa Catarina e Rio Grande do Sul.

A avaliação de impacto foi realizada utilizando o método de Controle Sintético Generalizado, recentemente desenvolvido por Xu (2017) e ainda não aplicado no Brasil. Essa metodologia permite a obtenção de um grupo de comparação representado por uma combinação de estados potenciais cuja evolução dos indicadores de pobreza no período pré-intervenção se aproxime daquela observada para o Ceará. Essa abordagem busca unificar o método de controle sintético proposto por Abadie et al. (2010) com modelos lineares de efeitos fixos, obtendo uma estrutura simples, da qual o método de Diferenças-em-Diferenças é um caso especial.

Os resultados permitem inferir impactos positivos do FECOP/CE traduzidos em uma trajetória de redução mais acentuada da pobreza e da pobreza extrema no estado. Tais resultados se mostraram estatisticamente significativos a partir de 2008. O impacto médio do FECOP ao longo do período analisado foi de aproximadamente $9,26 \%$ sobre o indicador de pobreza e de 12,6\% sobre o indicador de extrema pobreza. Entre 2004 e 2014, segundo estimativas do IPEA, o número de pessoas pobres no Ceará declinou de 4,5 milhões para 2,16 milhões, e o de extremamente pobres declinou de 2 milhões para menos de 813 mil. ${ }^{8}$ Considerando tais estimativas, o impacto das ações financiadas pelo FECOP representa redução de mais de 217 mil pessoas vivendo em situação de pobreza ao longo do período considerado.

As projeções das trajetórias desses indicadores apontam para uma continuidade dessa tendência, com ampliação dos impactos do FECOP. Além disso, após uma análise comparativa dos estados do controle sintético com o Ceará referente ao recebimento do Bolsa Família, acredita-se que esses efeitos não estejam sendo afetados pela ausência da variável que re8 Estimativas com base nos dados da PNAD (2004 e 2014), e a linha de pobreza, em necessidades calóricas. 
presenta esse repasse, uma vez que todos os estados participam do PBF, e que embora o repasse seja heterogêneo alguns estados apresentam valor equivalente ou superior ao estado do Ceará.

Embora este estudo tenha encontrado efeitos significativos do FECOP sobre a redução das taxas de pobreza e extrema pobreza no Ceará, esse efeito poderia ser potencializado se os projetos financiados pelo FECOP tivessem ações e público-alvo melhor definidos. Em iniciativa recente, o governo do estado promulgou o Decreto $\mathrm{n}^{\circ} 33.320$, de 24 de outubro de 2019, no qual estabelece "procedimentos para encaminhamentos de projetos à gerência executiva do FECOP (GEF), e institui critérios para análise e avaliação de projetos, para fins de deliberação do Conselho Consultivo de Políticas de Inclusão Social (CCPIS), e dá outras providências". Esse decreto visa promover melhores práticas na elaboração dos projetos, resultando em programas mais eficientes e que façam melhor uso dos recursos públicos.

Conforme aponta o presente artigo, o caso do FECOP/CE representa um exemplo interessante de estratégia de combate à pobreza em nível regional. Demostra que a avaliação de tais estratégias é algo factível e que podem ser generalizadas para a análise de outras experiências. Um apontamento pertinente para análises futuras consiste na extrapolação desse tipo de avaliação para outras experiências, contando inclusive com análises de custo efetividade das diferentes estratégias regionais e controlando os efeitos de outras políticas de combate à pobreza.

Deve existir um amplo esforço para adoção de sistemas de monitoramento e avaliação que possam aprimorar as políticas sociais de modo geral, não apenas as já existentes, mas estabelecer boas práticas desde a concepção e formulação das políticas públicas. A avaliação das políticas públicas deve começar no nascedouro, por meio da análise ex ante. É necessário que as políticas públicas contem com esse tipo de avaliação para que os recursos públicos e o bem-estar da sociedade sejam otimizados (Brasil, 2018).

\section{Referências}

ABADIE, A.; DIAMOND, A.; HAINMUELLER, J. Synthetic control methods for comparative case studies: Estimating the effect of California's tobacco control program. Journal of the American statistical Association, v. 105, n. 490, p. 493-505, 2010. 
ABADIE, A.; DIAMOND, A.; HAINMUELLER, J. Comparative politics and the synthetic control method. American Journal of Political Science, v. 59, n. 2, p. 495-510, 2015.

ADELMAN, I.; MORRIS, C. T. Economic growth and social equity in developing countries. Stanford: Stanford University Press, 1973.

ASSIS, D. N. C.; MEDEIROS, C. N. de; NOGUEIRA, C. A. G. Extrema pobreza infantil, crescimento e distribuição de renda. Planejamento e Políticas Públicas, n. 48, p. 175-205, jan/ jun 2017.

BAI, J. Panel data models with interactive fixed effects. Econometrica, v. 77, n. 4, p. 1.229-1.279, 2009.

BARROS, R. P.; CARVALHO, M.; FRANCO, S.; MEDONÇA, R. Uma análise das principais causas da queda recente na desigualdade de renda brasileira. Rio de Janeiro: IPEA, ago. 2006. Texto para discussão, n. 1.203.

BARROS, R. P.; CARVALHO, M.; FRANCO, S.; MEDONÇA, R. A importância da queda recente da desigualdade na redução da pobreza. Rio de Janeiro: IPEA, jan. 2007. Texto para discussão, n. 1.256.

BARROS, R. P.; CARVALHO, M.; FRANCO, S.; MEDONÇA, R. Determinantes da queda na desigualdade de renda no Brasil. Rio de Janeiro: IPEA, jan. 2010. Texto para discussão, n. 1.460.

BRASIL. Casa Civil da Presidência. Avaliação de políticas públicas: guia prático de análise ex ante Brasília: Ipea, 2018. v. 1. 192 p.

BRASIL. Emenda Constitucional n 31, de 14 de dezembro de 2000. Altera o Ato das Disposições Constitucionais Transitórias, introduzindo artigos que criam o Fundo de Combate e Erradicação da Pobreza, Fortaleza, CE. Diário Oficial da União, Brasília, DF, 18 dez. 2000. BOURGUIGNON, F. The poverty-growth-inequality triangle. Washington, DC: The World Bank. Dec., 2004. (Working Paper Series, n. 1585).

CAMPOS, A. G. Bem-estar social nos anos 1990 e 2000: traços etilizados da história brasileira. Brasília: IPEA, 2015. (Texto para discussão, n. 2015).

CARNEIRO, D. M.; BAGOLIN, I. P.; TAI, S. H. T. Determinantes da pobreza nas regiões metropolitanas do Brasil no período de 1995 a 2009. Nova Economia, v. 26, n. 1, p. 69-96, 2016.

CEARÁ. Decreto n 33.320, de 24 de outubro de 2019. Diário Oficial do Estado do Ceará, Fortaleza, CE, 29 out. 2019.

CEARÁ. Secretaria do Planejamento. Manual do Fundo Estadual de Combate à Pobreza. Fortaleza, 2014.

CEARÁ. Decreto n 29.910 , de 29 de setembro de 2009. Regulamenta a Lei Complementar Estadual, no 37 , de 26 de novembro de 2003, que institui o Fundo Estadual de Combate à Pobreza, e dá outras providências. Diário Oficial do Estado do Ceará, Fortaleza, CE, 30 set. 2009.

CEARÁ. Decreto n 33.320, de 24 de outubro de 2019. Estabelece procedimentos para encaminhamentos de projetos à gerência executiva do FECOP/GEF, e institui critérios para análise e avaliação de projetos, para fins de deliberação do Conselho Consultivo de Políticas de Inclusão Social (CCPIS), e dá outras providências. Diário Oficial do Estado do Ceará, Fortaleza, CE, 29 out. 2019.

CEARÁ. IPECE - Instituto de Pesquisa e Estratégia Econômica do Ceará. Portaria n. 13, de 09 de março de 2018. Diário Oficial do Estado do Ceará, série 3, ano X n. 47. Fortaleza, 2018. 
CHENERY, H.; AHLUWALIA, M. S.; DULOY, J. H.; BELL, C. L. G.; JOLLY, R. Redistribution with growth: Policies to improve income distribution in developing countries in the context of economic growth. Oxford: Oxford University Press, 1974.

DIAS, R. C. N.; SAIANI, C. C. S.; CARVALHO, C. E.; SILVA, A. L. P. D. Analysis of the distribution of World Bank disbursements in Latin America between 1985 and 2010. Nova Economia, v. 26, n. 2, p. 393-427, 2016.

DUCLOS, J.-Y. What is "pro-poor"? Social Choice and Welfare, v. 32, n. 1, p. 37-58, 2009.

ESPÍRITO SANTO. Decreto n. 3230-R, de 15 de janeiro de 2013. Aprova o Regimento Interno da Comissão de Acompanhamento (CA) do Fundo Estadual de Combate e Erradicação da Pobreza (FUNCOP) do Estado do Espírito Santo. Diário Oficial do Espírito Santo, Vitória, 15 de janeiro de 2013.

FILGUEIRAS, M. A. S. L. Um estudo sobre o Fundo Estadual de Combate à Pobreza: FECOP para o fortalecimento do patrimônio individual das famílias de baixa renda do Estado do Ceará. 75 f. Dissertação (Mestrado Profissional em Economia do Setor Público - Sobral) - Curso de Pós-Graduação em Economia, Universidade Federal do Ceará, CAEN, Fortaleza, CE, 2010.

FILHO, A. S. M. O mapeamento da pobreza e da cobertura dos programas governamentais nos municípios do estado do Ceará. 40 f. Dissertação (Mestrado Profissional) - Programa de Pós-Graduação em Economia, CAEN, Universidade Federal do Ceará, UFC, Fortaleza, CE, 2012.

FERREIRA-BATISTA, N.; CACCIAMALI, M. C. Migração familiar, trabalho infantil e ciclo intergeracional da pobreza no estado de São Paulo. Nova Economia, v. 22, n. 3, p. 515-554, 2012 .

FRANÇA, J. M. S.; MANSO, C. A.; BARRETO, F. A. F. D. Comparando a intensidade do crescimento pró-pobre entre as regiões brasileiras pós-plano real. Planejamento e Políticas Públicas, n. 38, 2012.

HOFFMANN, R. Transferências de renda e a redução da desigualdade no Brasil e cinco regiões entre 1997 e 2004. Econômica, v. 8, n. 1, p. 55-81, 2006.

HOFFMANN, R.; DE OLIVEIRA, R. B. The Evolution of Income Distribution in Brazil in the Agricultural and the non-agricultural Sectors. World Journal of Agricultural Research, v. 2, n. 5, 2014.

IJSN - INSTITUTO JONES DOS SANTOS NEVES. Sistema de Monitoramento e Avaliação de Políticas Públicas do Estado do Espírito Santo (SiMAPP). Vitória: IJSN, 2018. (Nota Técnica, n. 56).

IPECE - INSTITUTO DE PESQUISA E ESTRATÉGIA ECONÔMICO DO CEARÁ (2017).

MARINHO, E.; LINHARES, F.; CAMPELO, G. Os programas de transferência de renda do governo impactam a pobreza no Brasil? Revista Brasileira de Economia, Rio de Janeiro, v. 65 n. 3, p. 267-288, jul./set. 2011.

MELO FILHO, A. de S. O mapeamento da pobreza e da cobertura dos programas governamentais nos municípios do estado do Ceará. Dissertação (Mestrado Profissional) - Programa de Pós-Graduação em Economia, CAEN, Universidade Federal do Ceará, UFC, Fortaleza, 2012.

MIRO, V. H.; BARROS, L. A. M. Contabilizando os determinantes da redução na pobreza no Ceará (2004-2014). Ensaios sobre a Pobreza e a Desigualdade N²7 - Laboratório de Estudos da Pobreza. Fortaleza, 2018. 
MUNIZ, L. F. D. Contribuição do programa FECOP ao desenvolvimento do Ceará. 87 f. Dissertação (Mestrado Profissional) - Programa de Pós-Graduação em Economia, CAEN, Universidade Federal do Ceará, UFC, Fortaleza, CE, 2010.

NOGUEIRA, C. A. G.; FORTE, S. H. A. C. A eficácia das políticas de combate à pobreza e os desafios na priorização das intervenções nos municípios cearenses. Fortaleza: IPECE, 2016. Texto para discussão, n. 118.

NEVES, E. B. Fundo de combate à erradicação da pobreza no estado do Rio Grande do Norte (FECOP): análise da sua evolução e aplicação no período de 2009 a 2012. 45 f. Monografia (Graduação em Ciências Contábeis) - Universidade Federal do Rio Grande do Norte, Natal, 2013.

OLIVEIRA, V. R. de; JACINTO, P. de A. Crescimento pró-pobre ou empobrecedor? Uma análise para os estados brasileiros, no período 1995-2011. Nova Economia, v. 25, n. 1, p. 161-180, 2015.

RIBEIRO, L. L.; MARINHO, E. L. L. A new approach to poverty in Brazil: A bidimensional measurement of well-being. Nova Economia, v. 25, n. 2, p. 447-464, 2015.

ROCHA, S. Poverty upsurge in 2015 and the rising trend in regional and age inequality among the poor in Brazil. Nova Economia, n. Ahead, 2019.

SOARES, S. Análise de bem-estar e decomposição por fatores da queda na desigualdade entre 1995 e 2004. Econômica, Rio de Janeiro, v. 8, n. 1, 2006.

SOARES, F. V.; SOARES, S.; MEDEIROS, M.; GERREIRO, R. Programas de transferência de renda no Brasil: impactos sobre a desigualdade. Brasília: IPEA, out, 2006. Texto para discussão, n. 1.228 .

SHORROCKS, A. F. Decomposition procedures for distributional analysis: A unified framework based on the Shapley value. University of Essex, 1999. Mimeografado.

TEIXEIRA, F. F. C. Análise de resultados e impactos do FECOP nos municípios cearenses com ênfase na educação. 43 f. Dissertação (Mestrado Profissional em Economia do Setor Público) - Programa de Pós-Graduação em Economia, Universidade Federal do Ceará, Fortaleza, 2008.

TORRES, M. D. O.; VOSTI, S. A.; MANETA, M. P.; WALLENDER, W. W.; RODRIGUES, L. N.; BASSOI, L. H.; YOUNG, J. A. Spatial patterns of rural poverty: An exploratory analysis in the São Francisco River Basin, Brazil. Nova Economia, v. 21, n. 1, p. 45-66, 2011.

VICKERY, C. The Time-Poor: A New Look at Poverty. Journal of Human Resources, p. 27-48, 1977.

XU, Y. Generalized Synthetic Control Method: Causal Inference with Interactive Fixed Effects Models. Political Analysis, v. 25, n. 1, p. 57-76, 2017.

WORLD BANK. End extreme poverty and promote shared prosperity. Washington, D. C.: World Bank, 2013.

\section{Sobre os autores}

Vitor Hugo Miro C. Silva - vitormiro@ufc.br

Programa de Pós-Graduação em Economia Rural (PPGER), Universidade Federal do Ceará, Fortaleza, CE, Brasil.

ORCID: https://orcid.org/0000-0002-5392-8764. 
Francisca Zilânia Mariano-zilania@ufc.br

Professora dos cursos de Economia e Finanças da Universidade Federal do Ceará, Sobral, CE, Brasil. ORCID: https://orcid.org/0000-0002-1282-8812.

Guaracyane Lima Campêlo-guaracyane@ufc.br

Professora dos cursos de Economia e Finanças da Universidade Federal do Ceará, Sobral, CE, Brasil. ORCID: https://orcid.org/0000-0002-1962-138X.

Natália Cecilia de França - nc.franca@hotmail.com

Centro de Análise de Dados e Avaliação de Políticas Públicas, Instituto de Pesquisa e Estratégia Econômica do Ceará, Fortaleza, CE, Brasil.

ORCID: https://orcid.org/0000-0002-1119-3026.

João Mário Santos de França-joao.franca@ufc.br

Programa de Pós-Graduação em Economia, Universidade Federal do Ceará, Fortaleza, CE, Brasil. ORCID: https://orcid.org/0000-0001-6805-808X.

\section{Marilia Rodrigues Firmiano - marilia.firmiano@ipece.ce.gov.br}

Diretoria de Estudos de Gestão Pública, Instituto de Pesquisa e Estratégia Econômica do Ceará, Fortaleza, CE, Brasil. ORCID: https://orcid.org/0000-0001-7112-2855.

Os autores agradecem o apoio financeiro da Fundação Cearense de Apoio ao Desenvolvimento Científico e Tecnológico (Funcap), que viabilizou a realização do presente estudo, e ao Centro de Análise de Dados e Avaliação de Políticas Públicas (CAPP)/IPECE, pelo suporte físico e infraestrutura utilizada.

\section{Sobre $o$ artigo}

Recebido em 30 de abril de 2019. Aprovado em 05 de maio de 2020 